\title{
IS THE RELATIONSHIP BETWEEN MONETARY POLICY AND HOUSE PRICES ASYMMETRIC ACROSS BULL AND BEAR MARKETS IN SOUTH AFRICA? EVIDENCE FROM A MARKOV-SWITCHING VECTOR AUTOREGRESSIVE MODEL
}

Beatrice D. Simo-Kengne*, Mehmet Balcilar ${ }^{* *}$, Rangan Gupta ${ }^{* * *}$, Monique Reid $^{* * * *}$ and Goodness C. Aye

\begin{abstract}
This paper examines asymmetries in the impact of monetary policy on the middle segment of the South African housing market from 1966:M2 to 2011:M12. We use Markov-switching vector autoregressive (MS-VAR) model in which parameters change according to the phase of the housing cycle. The results suggest that monetary policy is not neutral as house price growth decreases substantially with a contractionary monetary policy. We find that the impact of monetary policy is larger in bear regime than in bull regime; indicating the role of information asymmetry in reinforcing the financial constraint of economic agents. As expected, monetary policy reaction to a positive house price shock is found to be stronger in the bull regime. This suggests that central banks react more in bull regime in order to prevent potential crisis related to the subsequent bust in house prices bubbles which are more prominent in bull markets. These results substantiate important asymmetries in the dynamics of house prices in relation to monetary policy, vindicating the advantages of generating regime dependent impulse response functions.
\end{abstract}

Keywords: Monetary policy, House prices, Regime switching JEL classification: C22, C32, E52, R31

\footnotetext{
* Department of Economics, University of Pretoria, Pretoria South Africa. Email: beatrice.simo kengne@up.ac.za.

** Department of Economics, Eastern Mediterranean University, Famagusta, Turkish Republic of Northern Cyprus, via Mersin 10, Turkey. Email: mehmet@mbalcilar.net.

${ }^{* * *}$ Corresponding author. Department of Economics, University of Pretoria, South Africa. Email: rangan.gupta@up.ac.za.

${ }_{* * * * *}$ Department of Economics, Stellenbosch University, Stellenbosch, South Africa. Email: mreid@sun.ac.za.

${ }^{* * * * *}$ Department of Economics, University of Pretoria, Pretoria, South Africa. Email: goodness.aye@up.ac.za.
} 


\section{Introduction}

The recent global economic downturn attributed to the sub-prime crisis in the US with rapid contagion worldwide has attracted the attention of academics and policymakers of both developed and developing countries, and South Africa is no exception . As observed during the "Great Recession", the bursting of the house price bubble is generally followed by significant contractions in the real economy. ${ }^{1}$ Over the last two decades, South Africa has witnessed a rapid appreciation in home values which has been shown to have affected the real economy, through consumption, at both aggregate and provincial levels (Das et al., 2011; Ncube and Ndou, 2011; Peretti et al., forthcoming; Simo-Kengne et al., 2012, forthcoming). ${ }^{2}$ Furthermore, Gupta and Hartley (forthcoming) point out that house price in South Africa, is a leading indicator for output and inflation, and hence, can provide important information as to where the real economy is heading. Given this, it is crucial for central banks to analyze thoroughly the effects of monetary policy on asset prices in general and real estate in particular, which in turn, would lead to the understanding of the effects of monetary policy on the economy at large. ${ }^{3}$

Against this backdrop, the main objective of this paper is not only to analyze the impact of interest rate on South African house prices, but also, to check if the effect is asymmetric depending on whether the housing market is in a bull or bear regime. Intuitively, an increase in the interest rates tends to increase the user cost of capital which translates into a decrease in housing activity and consequently a fall in real estate prices (Demary, 2010). Furthermore, the class of models developed by Bernanke and Gertler (1989) and Kiyotaki and Moore (1997), in which there exist agency costs of financial intermediation (finance constraint) asserts that when there is information asymmetry in the financial market, agents may behave as if they were constrained financially. Moreover, the financial constraint is more likely to bind in bear markets. Hence, a monetary policy may have greater effects in bear markets. Furthermore, recent studies by Ncube and Ndou (2011), Peretti et al. (forthcoming), Simo-Kengne et al. (forthcoming), highlight that the South African Reserve Bank (SARB) has systematically reacted to house price movements. ${ }^{4}$ Given the possibility of a feedback of house prices onto the interest rate setting behavior of the SARB, we use a Markov-switching vector autoregressive (MS-VAR) model comprising the interest rate and house price, rather than the standard Markov switching regressions popularly used when analyzing the impact of monetary policy on asset returns (mainly stock returns), ${ }^{5}$ which in turn, assumes exogeneity of the monetary policy instrument. ${ }^{6}$

\footnotetext{
${ }^{1}$ Recently, Leamer (2007) strongly argues that housing is the business cycle, indicating "any attempt to control the business cycle needs to focus especially on residential investment." (p. 150). His main point relates to the dynamics of the construction of homes. To wit, a building boom over one time interval pushes the stock of new homes above trend and that necessitates with some lag another time interval with a building slump. Thus, monetary policy should focus on preventing booms from occurring to head off the eventual slump. Smets (2007) provides commentary on Leamer's (2007) paper and argues that interest rates (and monetary policy) crucially determine the linkages between the housing cycle and the business cycle. Leamer (2007) responds that "in the context of my paper, the interest rate spread has its impact though housing, though it surely operates through other channels." (p. 249).

${ }^{2}$ For a detailed international literature review on the impact of house prices on the real economy, the reader is referred to André et al. (2011), Peretti et al. (forthcoming), and Simo-Kengne et al. (forthcoming).

${ }^{3}$ For a detailed international literature review on the impact of interest rate on house prices, the reader is referred to Vargas-Silva (2008), Gupta and Kabundi (2010), Gupta et al., (2012a, b).

4 Note that, Naraidoo and Ndahiriwe (forthcoming) and Naraidoo and Raputsoane (2010) using linear and nonlinear Taylor rules had indicated that the SARB reacts to a financial conditions index, which included real house prices, besides, real effective exchange rate, real stock prices and credit spread. For a detailed international literature review on the response of monetary policy to asset prices the reader is referred to André et al. (2011) and Peretti et al. (forthcoming).

5 The reader is referred to Napolitano (2006) for a detailed literature review.

${ }^{6}$ As far as the housing market is concerned, studies such as Garino and Sarno (2004), Xiao and Tan (2006) and Feng and Li (2011) have used univariate Markov-switching unit root tests to detect house price bubbles in the UK, Hong Kong and Seoul, and Beijing, respectively. Prior to that Hall et al. (1997) had used a univariate Markovswitching error correction approach to model the housing cycle in the UK.
} 
On one hand, the MS structure allows us to characterize the time series dynamics in different states, and on the other hand, the VAR structure allows for possible endogeneity in the relationship between monetary policy and house prices. To the best of our knowledge, the study by Chang et al. (2011) is the only other existing study that has utilized the MS-VAR approach to analyze the impact of monetary policy on housing returns (besides equity real estate investment trusts and stock returns) for the US. Though this paper does not provide a clear identification of the housing cycle in terms of bull and bear markets, the authors indicate that, following an innovation in Federal Funds rate, housing returns decline substantially more in low-volatility regime than in high-volatility regime. However, this paper did not analyze the possible feedback from housing returns to interest rate. More importantly, with no confidence intervals provided for the impulse response functions generated from the MS-VAR model, one cannot gauge whether the effects were significant or not.

Though a few studies, namely, Gupta and Ndahiriwe (2010), Gupta et al. (2010) and Ncube and Ndou (2011), indicate a negative impact of monetary policy on house prices in South Africa, none of these studies investigated the possible asymmetry in this effect. Further, studies, such as Ncube and Ndou (2011), Peretti et al. (forthcoming), Simo-Kengne et al. (forthcoming), which analyzes the plausibility of a feedback from housing prices onto interest rate, did not say anything about the nature of this relationship during bull and bear housing markets. The reason being that all these studies, except Peretti et al. (forthcoming), used linear (structural and factoraugmented)VAR models, and hence, could not account for possible non-linearities in the relationship between interest rate and house prices that could exist under different states of the housing market. Peretti et al. (forthcoming) used a time-varying parameter VAR model, which accounted for non-linearities in the relationship between consumption, interest rate and house prices, and was able to depict the changes in the nature of this relationship over time. However, this paper, did not discuss how monetary policy reacted to house price movements during bear and bull markets, though it could have, having identified the regimes.

South African housing market is categorized into luxury, middle and affordable segments based on the price of the properties, with the middle-segment being further divided into, large, medium and small based on sizes of the houses. ${ }^{7}$ In this paper, besides analyzing the entire middle-segment, we also look at the different size category of this segment, to capture possible heterogeneity in the relationship between house prices and interest rate. Given that a MS-VAR is parameter intensive, we use the maximum possible span of monthly data covering the period of 1966:1-2011:12, which is a departure from the quarterly data-based earlier studies related to house prices and interest rate in South Africa. In this regard, note that, with house price being identified as a leading indicator, Gupta (2012) emphasizes that one should carry out the analysis on housing markets at the highest possible frequency. Due to this, we had to rule out the luxury and affordable sections of the housing market, since data on these two segments are only available at quarterly frequency. However, with Gupta et al. (2010), Das et al. (2011) and Gupta and Inglesi-Lotz (forthcoming) indicating that policies does not significantly affect these two extreme ends of the market, we believe, that the compromise in the form of losing information on the luxury and affordable segments by using monthly frequency, is not a serious one. As in the existing literature on housing markets and interest rate in South Africa, the monetary policy instrument is chosen to be the three months Treasury bill rate. ${ }^{8}$ Ultimately, we look at four sets

\footnotetext{
${ }^{7}$ See Section 3 on the data used for further details.

${ }^{8}$ It is believed that the housing market is unlikely to respond to policy actions that were already anticipated. Therefore, we utilized a measure of monetary policy surprise for our case, originally developed by Gupta and Reid (2012) to analyze its impact on stock returns in South Africa. The monetary policy surprise was constructed using the change in the three month Banker's Acceptance rate on the day after the Monetary Policy Committee announces the official repurchase rate decision. Monthly values for the surprises were obtained by taking averages of the eventbased data if there were multiple Monetary Policy Committee meetings in a month, and when there was no such
} 
of bivariate MS-VAR models ${ }^{9}$ comprising real house price of the entire, large, medium and small middle-segments considered individually, along with the three months Treasury bill rate. The rest of the paper is structured as follow: Section 2 briefly presents the Markov switching framework and discusses the estimation and identification procedures, while Section 3 describes the data used. Section 4 reports the empirical results with regard to the potential asymmetric effects of monetary policy on house prices and vice versa. Finally, Section 5 concludes.

\section{Methodology: Markov-Switching Vector Autoregressive (MS-VAR) Model}

The use of the Markov-switching approach has become popular for determining asymmetries. This methodology initially appeared in the form of switching regressions in Golfeld and Quandt (1973), and underwent a number of extensions and refinements. Hamilton (1989) and Krolzig (1998) made important contributions by combining switching models with vector autoregression to develop a MS-VAR which is well equipped to characterise macroeconomic fluctuations in the presence of structural breaks or shifts. Applied to the housing market, the Markov-switching framework offers the possibility to model booms and contractions as switching regimes of the stochastic process that generates the growth rate of the housing prices. As discussed above, given our interest in studying the possible feedback from house prices to the interest rate behaviour of the SARB, besides analyzing the effect of the monetary policy on house prices, we look at a MS-VAR. The MS-VAR also allows us to analyze impulse response functions to tract the dynamic of the variables of concern following shocks to the system.

A special case of the MS-VAR framework is the MSIAH(m)-VAR(p) model, in which all parameters of the autoregression including the intercept term and the variance are allowed to switch between regimes. Let $\mathrm{Y}_{\mathrm{t}}$ be a bivariate VAR in monetary instrument (Tbill) and real house price growth (ghp) of either the entire middle-segment or its respective size categories, used individually. Based on all the standard unit root tests, namely, Augmented Dickey-Fuller (1981) (ADF), Phillips-Perron (1988) (PP), Dickey-Fuller test with generalized least squares detrending (DF-GLS), the Kwiatkowski, Phillips, Schmidt, and Shin (KPSS) (1992) test; the Elliot, Rothenberg, and Stock (ERS) (1996) point optimal test, the Ng-Perron (2001) modified versions of the PP (NP-MZt) test and the ERS point optimal (NP-MPT) test, all the real house prices were found to be non-stationary, so the real house price measures were converted to their corresponding growth rates, and denoted ghp. The nominal interest rate was found to be stationary at the 10 percent level of significance using ADF, DF-GLS, ERS, NP-MZ $\mathrm{H}_{\mathrm{t}}$ and NP$\mathrm{MP}_{\mathrm{T}}$ tests, and hence, was used in levels, and denoted as Tbill. ${ }^{10}$ As in Ehrmann, Ellison and

meetings held in a particular month, the value of the surprise for that specific month was set to zero. The data covered the period of 2000:1-2011:12. Since, this measure is exogenous, we used a Markov-switching regression framework instead of a MS-VAR model. The results indicate that sudden adjustments occur contemporaneously in the dynamics of house prices due to unanticipated changes in monetary policy. House prices decrease with the increase in the monetary surprise, with a significant effect being reported in the bear regime. Moreover, the asymmetric effect of monetary policy emerges in all market segments; the coefficients being different in size and or signs across the states. Additionally, the bear market appears to be the most affected for all categories except the small segment, which shows a significant effect in the bull regime. In the same vein, we carried out our analysis treating the three month Treasury bill rate as exogenous using Markov-switching regressions. However, given that the fit of the MS-VAR models were consistently better than the Markov-switching regressions, indicative of, perhaps, the endogeneity of the three months Treasury bill rate, these results were suppressed to save space. Moreover, the MS-VAR approach offers the possibility to analyze joint dynamics, which in turn, better characterizes the behavior of financial time series. The details of all these results are available upon request from the authors.

9 The reason for not including all the house prices together in a MS-VAR is to avoid the possible multicollinearity between the house price index for the entire middle segment and the house price indices of its three sub-categories. Besides, it is not advisable to go beyond three-variable MS-VARs due to the problem of overparameterization leading to imprecise inferences (Perlin, 2011).

10 These results are available upon request from the authors. 
Valla (2003), the joint dynamics of (Tbill, ghp) are given by the following MSIAH-VAR specification:

$$
Y_{t}= \begin{cases}\mu_{1}+B_{11} Y_{t-1}+\ldots+B_{p 1} Y_{t-p}+A_{1} \varepsilon_{t} & \text { if } s_{t}=1 \\ \mu_{2}+B_{12} Y_{t-1}+\ldots+B_{p 2} Y_{t-p}+A_{2} \varepsilon_{t} & \text { if } s_{t}=2\end{cases}
$$

We identify the housing demand and the monetary policy shocks using a recursive or Choleski identification scheme. We order the variables as follows:Tbill and ghp following Musso et al. (2011) and André et al. (2011). Note that the latent variable $\mathbf{s}_{\mathrm{t}}$ which indicates bull or bear markets conventionally corresponds to "the high mean growth rate of house prices and stable state" and "low mean growth rate of house prices and volatile state" respectively. The fundamental residuals $\left(\varepsilon_{\mathrm{t}}\right)$ are assumed to be uncorrected at all leads and lags and their variance is set to unity so as to ensure the identity variance-covariance matrix. However, as each fundamental residual is pre-multiplied by a switching matrix $\mathrm{A}_{\mathrm{i}}$, the variance-covariance matrix $\Sigma_{i}$ of the structural disturbances $A_{i} \varepsilon_{t}$ is regime-dependent as indicated by the following transformation:

$$
\sum_{\mathrm{i}}=\mathrm{E}\left(\mathrm{A}_{\mathrm{i}} \mathrm{u}_{\mathrm{t}} \mathrm{t} \mathrm{u}_{\mathrm{t}}^{\prime} \mathrm{A}_{\mathrm{i}}^{\prime}\right) \quad \mathrm{A}_{\mathrm{i}} \pm\left(\mathrm{u}_{\mathrm{t}} \mathrm{u}_{\mathrm{t}}^{\prime}\right) \mathrm{A}_{\overline{\mathrm{i}}}^{\prime} \quad \mathrm{A}_{\mathrm{i}} \mathrm{I}_{2} \mathrm{~A}_{\mathrm{i}}^{\prime} \quad \mathrm{A}_{\mathrm{i}} \mathrm{A}_{\mathrm{i}}^{\prime}
$$

The main characteristic of MS-VAR is that dynamics of variables are conditioned on the unobserved Markov process followed under the regime. Because the Markov chain is unobservable, Ehrmann et al. (2003) emphasise that the recursive nature of the likelihood function prevents standard estimation techniques from providing the maximised likelihood. One alternative suggested by Krolzig (1997) is the iterative maximum likelihood estimation technique known as Expectation-Maximisation (EM) algorithm which is designed for a general class of models where the observed time series depends on some hidden stochastic variables. This estimation technique consists of two steps whereby the Expectation step infers the hidden Markov chain conditioned on a given set of parameters and the Maximisation step re-estimates the parameters based on the inferred unobserved Markov process. These steps are repeated until convergence.

One major attraction of the MS-VAR is the possibility of regime-dependent Impulse Response Functions (IRFs), which helps determine the cyclical variation in the responses of variables to a particular shock. Equation (3) gives the mathematical definition of the regimedependent IRFs for regime $i$. It traces the expected path of the endogenous variables at time $t+b$ following a one standard deviation shock to the $k$-th initial disturbance at time $t$, conditional on regime $i$ (Ehrmann et al., 2003).

$$
\theta_{\mathrm{ki}, \mathrm{h}}=\left.\frac{\partial \mathrm{E}_{\mathrm{t}} \mathrm{Y}_{\mathrm{t}+\mathrm{h}}}{\partial \mathrm{u}_{\mathrm{k}, \mathrm{t}}}\right|_{\mathrm{s}_{\mathrm{t}}=\ldots \mathrm{s}_{\mathrm{t}+\mathrm{h}} \mathrm{i}} \quad \text { for } \mathrm{h} \geq 0
$$

Recall that EM algorithm only provides estimates of the variance-covariance matrix $\sum_{\mathrm{i}}$ and not the matrices $A_{i}$. To make structural inferences from the data, the structural disturbances and hence $A_{i}$ must be identified. In other words, sufficient restrictions are imposed on the 
parameter estimates in order to derive a separate structural form for each regime, from which regime-dependent IRFs are then computed. As in a standard VAR measuring the housing effect of monetary policy, the house prices index is ordered last with the assumption that housing market reacts directly to changes in monetary policy. This is known as recursive identification scheme based on which the estimated variance-covariance matrix $\hat{\Sigma}_{\mathrm{i}}$ obtained by Choleski decomposition is used to identify the matrix $\hat{\mathrm{A}}_{\mathrm{i}}$. Through the standard bootstrapping technique, $\hat{\mathrm{A}}_{\mathrm{i}}$ are combined with the parameter estimates of the Markov-switching unrestricted $\mathrm{VAR}^{11}$ to derive the response vectors. The bootstrapping procedure consists of creating artificial histories for the variables based on which the distribution of the estimated parameters is approximated. This distribution shapes the confidence bands required for the impulse response analysis; the crucial step being the simulation of the hidden regime $s_{t}$. As in Chib (1996), the states are simulated using Forward Filter-Backwards Sampling (FFBS) known as Multi-Move algorithm. The confidence bands are obtained by Markov Chain Monte Carlo (MCMC) simulation with Gibbs sampling of 5000 draws with a burn-in of 2000 .

\section{Data}

The data sample covers the monthly house price indexes for the period of 1966:01 until 2011:12. Though the three-month Treasury bill rate data is available since 1957, we were constrained by the availability of the house price data, which in turn, determined the starting point of the analysis. The three-month seasonally adjusted Treasury bill rate data and the Consumer Price Index (CPI) data (used to convert nominal house prices into its real counterpart) are derived from the International Financial Statistics of the International Monetary Fund. Amalgamated Bank of South Africa (ABSA), one of the major private banks in South Africa, provides the seasonally adjusted house price index. As discussed earlier, ABSA categorizes housing into three price segments, namely luxury (ZAR 3.5 million - ZAR 12.8 million), middle (ZAR 480,000 - ZAR 3.5 million) and affordable (below ZAR 480,000 and area between 40 square metres - 79 square metres). The middle-segment is further categorized into three more segments based on sizes, namely large-middle (221 square metres - 400 square metres), medium-middle (141 square metres - 220 square metres) and small-middle (80 square meters - 140 square meters). The stable MS-VAR is estimated based on two lags, as was unanimously suggested by all the popular lag-length tests, namely, the sequential modified LR test statistic, the Akaike information criterion, the Schwarz information criterion, applied to a constant parameter VAR. ${ }^{12}$ Accounting for lags, our effective sample period start from 1966:04.

\section{Empirical results}

The MSIAH-VAR ${ }^{13}$ type of MS-VAR model is considered and the estimated coefficients are used to compute the IRFs. The choice of MSIAH type is motivated by the specification tests in Table 1 which clearly indicate a strong evidence of non-linearity, non-normality and heteroskedasticity for the four models corresponding to the entire middle segment and each of its sub-segments. Given these properties, regime dependent IRFs are meaningfully applied with a small number of regimes. We set two regimes prior to the estimation of the model to identify bear and bull markets. As noted earlier, states are differentiated not only by their average growth

\footnotetext{
11 Refer to Ehrmann et al. (2003) for details on characteristics and computation of the regime-dependent impulse responses.

12 The linear VAR is found to be stable as all roots were found to lie within the unit circle. The details of the laglength test along with the results indicating the stability of the VAR, is available upon request from the authors.

${ }^{13}$ MSIAH is also known as the heteroskedastic intercept switch model.
} 
rate but also by their variances. The results presented in Table 3 support the presence of two regimes. The growth rate of house prices is more volatile in regime 1 than in regime 2 , and the intercept is also lower in regime 1 than regime 2. Thus, regime 1 is identified as a bear market and regime 2 corresponds to a bull market.

Table 1: Specification Tests and Regime Properties

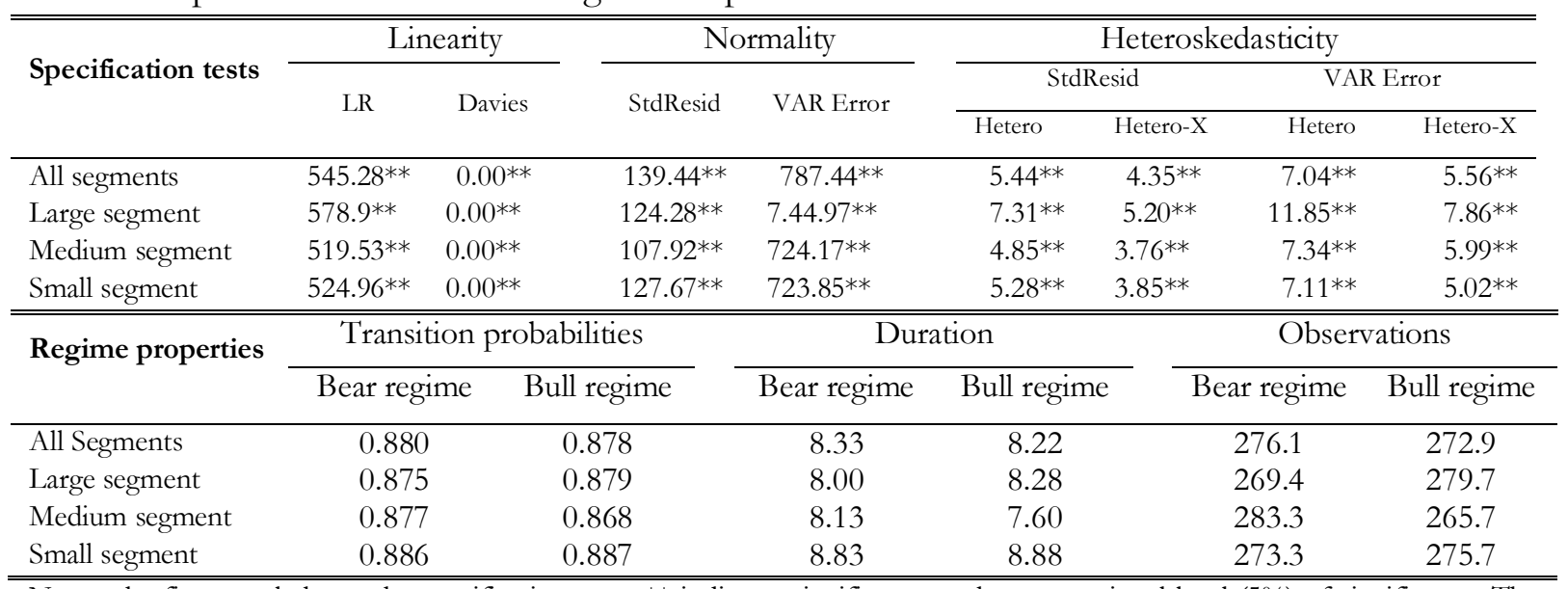

Notes: the first panel shows the specification tests; ${ }^{* *}$ indicates significance at the conventional level $(5 \%)$ of significance. The second panel displays the regime properties.

The sample properties of the data for each of the individual market segment are summarised in the first panel of Table 1. The appropriateness of the Markov switching model for the sample data is judged on the basis of the linearity tests. The LR tests the presence of two separate regimes in a linear system (Quandt, 1960) while Davies tests the presence of structural break under nuisance parameter (Davies, 1977). For all market segments, the Markov switching model turns out to be the preferred specification relative to the linear alternative. We also report the normality tests which test whether the skewness and kurtosis of the residuals correspond to that of the normal distribution (Doornik and Hansen, 1994). Under the null of normality, these tests give appropriate rejection frequencies based on chi-square critical values. Finally, following White (1980), the hetero test and hetero-x test for heteroskedasticity are conducted under the null of unconditional homoskedasticity. The hetero test relies on an auxiliary regression of the squared residuals on the original explanatory variables and their squares while the hetero-x test is based on a similar design, but accounts for the cross-products of the original regressors as arguments in the auxiliary regression. The evidence of heteroskedasticity is confirmed for all market segments by means of Chi-square critical values.

\subsection{Regime properties}

The second panel of Table 1 displays the regime properties for each of the individual housing market. In general, the regimes are persistent with the transition probabilities lying between 0.87 and 0.89 . For instance, the probability of being in bear market in time $t$ when the state of market was bear in t- 1 is 0.88 . In other words, market stays in bear regime for about 8 months on average which is quite persistent for a financial market. The timing of the change is similar across regimes with an average expected duration of about 8 months for the first three models (All, Large and Medium segments) and 9 months for the fourth model (Small segment). As indicated by the sum of observations per regime,the number of months for which the housing markets were under the two regimes, are very similar as well. Inferences regarding the turning points can be obtained from the smoothed probabilities of regime 2 (bull market), as depicted in Figure 1. It seems that the bear market is the prevailing regime between periods of 1966 to 
1970, 1976 to 1979 and 2001 to 2011 in the middle sector of South African housing market. These periods coincide with some important economic features and socio-political conditions that prevailed in South Africa.

The first downswing period matches the residential segregation reinforced by the Group Areas Act 36 of 1966 which forced people of different races to live in separate residential areas (Prinsloo and Cloete, 2002) with huge consequences on property prices (Koetze, 1999). The second period coincides with the 1976 Soweto student uprising which had an adverse effect on confidence and economic performance, leading to a decline in real house prices by 22.4 percent between 1976 and 1979 (Luüs, 2005). The last downswing is partly attributed to the effectiveness of the monetary policy in stabilising financial markets, especially given that the SARB moved to an inflation targeting regime starting in the February of 2000. Moreover as depicted by Naraidoo and Ndahiriwe (forthcoming) and Naraidoo and Raputsoane (2010) using linear and non-linear Taylor rules, the SARB had systematically been reacting to a financial conditions index, which included real house prices, during this period. It is also likely that the recent economic turmoil coupled with the Euro crisis, towards the end of the sample, has contributed to depressing real house prices through the slowdown of the South African economy in general.

On the other hand, Figure 1 indicates two periods of bull markets (regime 2) in the housing market, namely 1970 to 1976 and 1980 to 2000. While the first period of housing boom can be associated with the global inflation due to oil price shock resulting in a hike of construction costs, we can infer that loose monetary policy contributed to the substantial run-up in house prices between 1980 and $2000^{14}$. As discussed in Luüs (2005), the upward trend of the property prices in the early 1980s was mainly due to the gold price boom and a reduction in tax rates which boosted the household net wealth and facilitated a reduction in the mortgage lending rate. However, the increasing political pressure and the decrease in gold price resulted in higher interest rates, and depressed the property market from 1984; but the effect was restrained by financial liberalisation which took place in 1985 following the recommendations of the De Kock Commission. The easy availability of credit following the liberalization led to a consumption boom (housing and non housing goods), which, in turn, translated into sizable real estate appreciations ${ }^{15}$. This trend slowed down in 1991 with the political uncertainty about the future of the country. However, with the confidence restored in 1994 with democracy, a recovery in the housing market was observed mainly due to higher economic growth and lower inflation and interest rates. However, the contagion effect from the Asian crisis in 1996-1997 led to the fall in the value of the rand with significant rise in interest rates, and thus discouraging housing activities but by late 1999, the house price boom resumed.

\footnotetext{
${ }^{14}$ Housing may also have been seen as a hedge against inflation, leading to a higher housing demand and hence real estate prices.

15 The causality may also run the other way round: financial liberalisation led more credit translated into more housing demand, higher house prices and hence more consumption through the wealth and collateral effects
} 
Figure 1: MSIAH-VAR- Smooth Probabilities of Regime 2 (Bull Market)
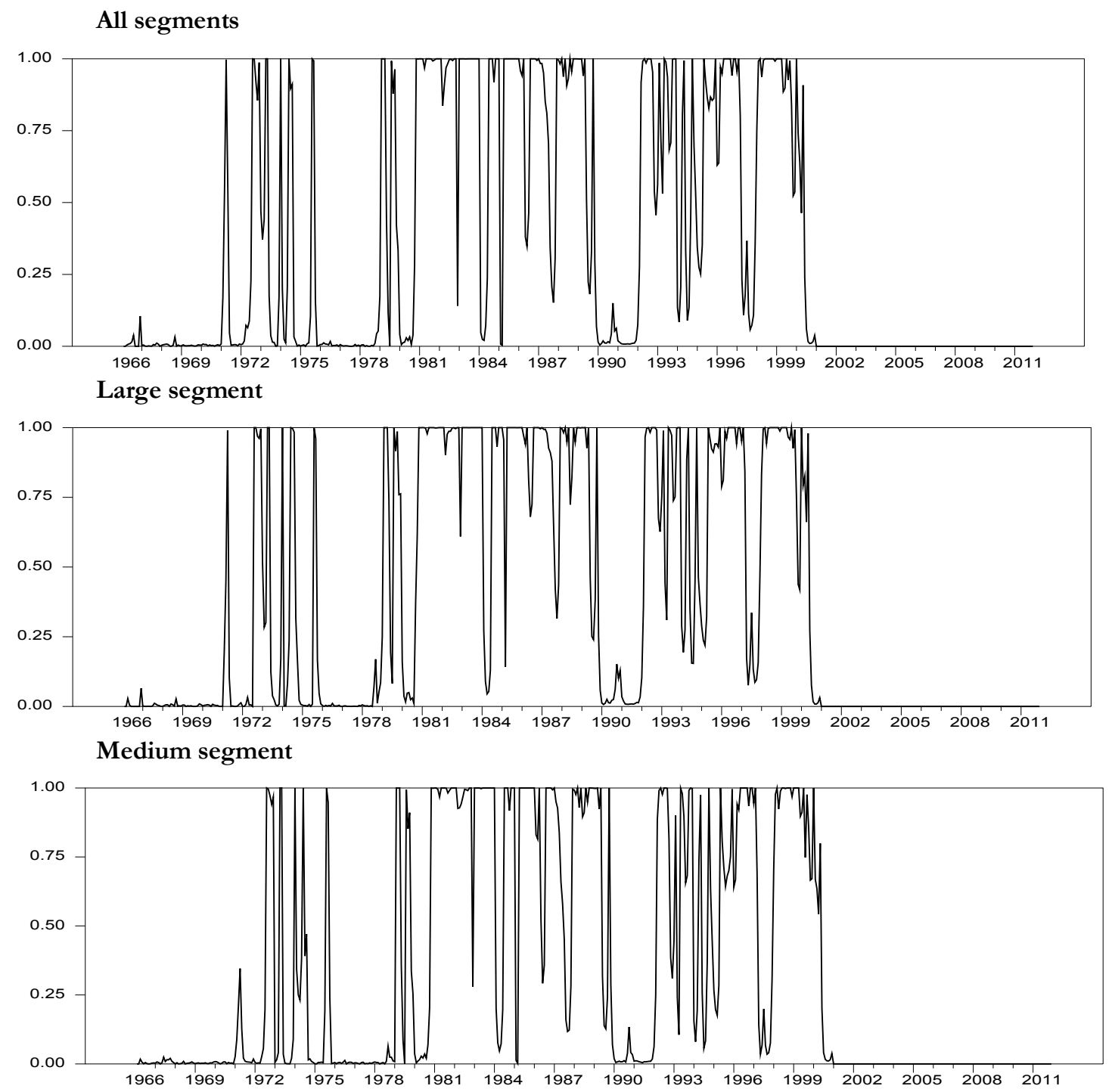

Small segment

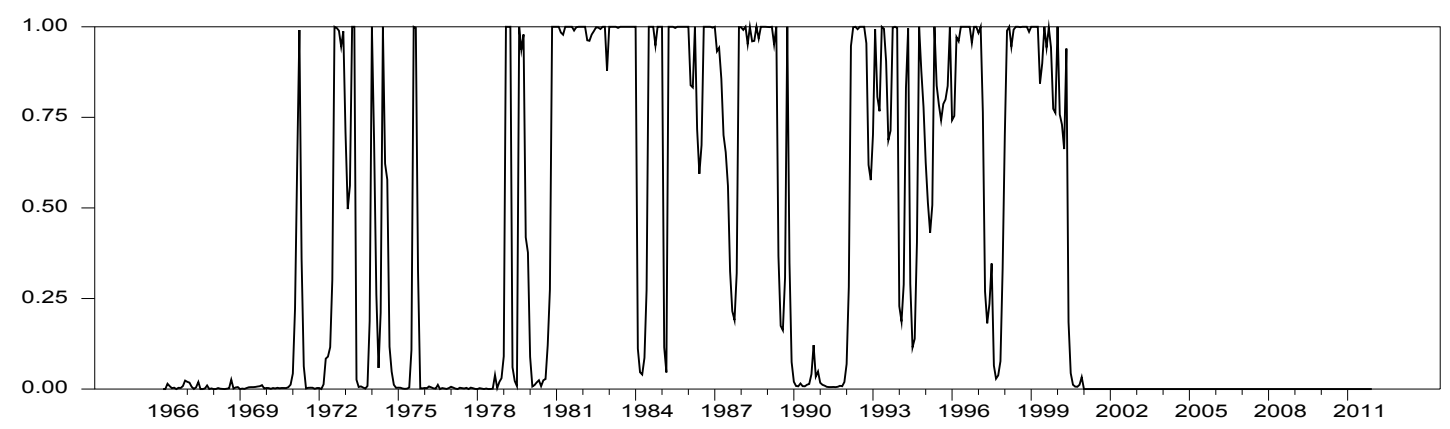




\subsection{Housing markets Synchronisation}

The similar pattern observed with smooth probabilities across segments raises the issue of potential synchronisation of the different market segments. Synchronisation tests ${ }^{16}$ developed by Harding and Pagan (2006) could not reject this hypothesis. In contrast of Harding and Pagan (2006) who used regime classification from a non-parametric NBER type rule, our regime classification or dating is based on smooth probability statistics ${ }^{17}$, which is 1 for regime $j$ if its probability is the maximum ${ }^{18}$. Focusing on the first panel of Table 2 , the concordance indices (upper diagonal) are reported to capture the degree of synchronisation of cycles, that is, the fraction of time housing cycles are in the same regime. Reported values are large, suggesting that housing cycle in the three selected market segments spends much of the time in the same regime (Bull in this case). Moreover, the pairwise correlations (lower diagonal) are typically high, indicating a strong correlation between states in different market segments.

There is also evidence of serial correlation in the states across segments ${ }^{19}$. For instance the first order serial correlation coefficient in the regime dummy series is around 0.94; highlighting the need to use robust variance matrix in the tests. We, therefore, use Newey-West (1987) heteroskedasticity and autocorrelation consistent standard errors with Barlett weights to perform the tests in Panel C. Robust t-statistics in the second panel (lower diagonal) of Table 2 show that the evidence for the null hypothesis of no market synchronisation is strongly rejected. Giving this, we first test for the necessary condition for perfect synchronisation. Results from panel $\mathrm{C}$ in Table 2 show a high p-value (0.991), suggesting that the null hypothesis that necessary condition holds (that is, the mean of regime dummy variable is equal across segments) cannot be rejected. Second, we perform the test of strong multivariate non-synchronisation based on the null of no synchronisation. Again, results are favourable to strong multivariate synchronisation as p-value is apparently very small (0.000). Third, with a high p-value of 0.995 , the test for strong perfect positive synchronisation could not reject the null hypothesis of perfect positive synchronisation.

Consequently, there is strong evidence in favour of perfect positive synchronisation in these market segments. They move simultaneously; indicating that regime of one market cannot be used in advance to predict the regime of others. We conclude that there is no leading market.

\footnotetext{
16 As aggregate series, "All segment" was excluded in the test since it is most likely to lead the synchronisation result. Furthermore, we did not test for negative synchronisation as this is not applicable in our case.

${ }^{17}$ We provide the results for Bull market since probability of Bear market=1-probability of bull market; leading to similar results.

18 The reader is referred to Harding and Pagan (2006) for technical details.

${ }^{19}$ We did not report the multivariate ACF, but results are available from the authors upon request.
} 
Table 2: Synchronisation tests

Panel A: Concordance indices (Upper) and Correlation (Lower) of housing cycles for selected market segments

\begin{tabular}{|c|c|c|c|}
\hline & Large segment & Medium segment & Small segment \\
\hline Large segment & …........ & 0.974 & 0.967 \\
\hline Medium segment & 0.948 & ............... & 0.970 \\
\hline All segment & 0.934 & 0.942 & ............. \\
\hline Mean & 0.498 & 0.487 & 0.517 \\
\hline \multicolumn{4}{|c|}{$\begin{array}{l}\text { Panel B: Standard (upper) and Robust t-statistics (Lower) for the null hypothesis of no } \\
\text { correlation of classical housing cycle states for selected market segments }\end{array}$} \\
\hline & Large segment & Medium segment & Small segment \\
\hline Large segment & …......... & 69.4 & 60.7 \\
\hline Medium segment & 63.8 & ............... & 65.4 \\
\hline All segment & 42.4 & 50.0 & ............ \\
\hline
\end{tabular}

Panel C: Non parametric tests of synchronisation

\begin{tabular}{l|cc}
\hline & Statistic & P-Value \\
\hline $\begin{array}{l}\text { Test for the necessary conditions for } \\
\text { perfect synchronisation across three } \\
\text { housing market segments }\end{array}$ & 0.018 & 0.991 \\
\hline $\begin{array}{l}\text { Test for strong multivariate non- } \\
\text { synchronisation }\end{array}$ & $1.1710^{14}$ & 0.000 \\
\hline $\begin{array}{l}\text { Test for strong perfect positive } \\
\text { synchronisation }\end{array}$ & $2.7510^{-2}$ & 0.995 \\
\hline \hline
\end{tabular}

Notes: Panel A displays the concordance indices constructed upon phase states for binary housing cycles and analogue of $\operatorname{Pr}\left(\mathrm{S}_{\mathrm{xt}}=\mathrm{S}_{\mathrm{yt}}\right)$ advocated in Harding and Pagan (2006). These indices have a maximum value of unity when $S_{x t}=S_{y t}$ and zero when $S_{x t}=\left(1-S_{y t}\right)$. Panel $B$ shows standard and robust t-statistics which account for both heteroskedasticity and autocorrelation. Panel C reports three synchronisation tests computed based on regime dummy variable using smooth probability of Bear market. 


\subsection{Regime dependent impulse responses}

The empirical analysis focuses on IRFs as economic inference from the autoregressive coefficients might be difficult, if not misleading, given that the model is essentially an atheoretical representation of the dynamics between interest rate and house prices. As is obvious from Table 2 , we, however, find that almost all the autoregressive coefficients are statistically significant, and the simple Wald test of asymmetry indicates that these coefficients are significantly different across regimes, except for the entire middle segment. Furthermore, the coefficients on the two lags of the growth rate of house prices in the first equation (Tbill equation) of the system add up to $0.499,0.571,0.613,0.635$ (regime 1) and $0.811,0.744,0.799,0.805$ (regime 2) for the four models respectively. This suggests considerable interest rate smoothing by the SARB.

Figure 2 displays the IRFs of real house price inflation of the different models with the 16 percent and 84 percent quantiles for the impulse responses resulting from a 100 basis point shock to the Treasury bill rate over a period of thirty-six months. Regardless of the category, the Tbill rate reaches a peak of 1.5 percent (1.8 percent) in the bear regime (bull regime) and stays significant throughout the three-year period. The resulting response of the real house price growth rates, following a contractionary monetary policy, is negative in general for all four categories. However, a few remarks are worth mentioning: First, in terms of magnitude and persistence, the responses of real house price inflation to a contractionary monetary policy differ considerably across regimes, hence, justifying the need of generating regime dependent impulse responses; Second, the initial rise of all and medium segment house prices observed in the bear regime following a monetary shock reflects the so-called house price puzzle often observed in the monetary policy and housing market literature that employs limited information sets contained in small-scale VARs based on a Choleski (recursive) decomposition for the identification of shocks. ${ }^{20}$ However, the puzzling effect of a rise in real house price growth rates following a contractionary monetary policy is marginal and/or short-lived, as it lasts about two months; Finally, the impact of monetary policy appears stronger, but with short-lived significance in the bear regime, compared to the bull regime, in which the effect is of smaller magnitude but more persistent, with significance holding for the entire period of 3 years following the shock. The results are indicative of asymmetric effects across regimes for both the interest rate and house prices emanating from a monetary policy shock.

As argued by the theoretical models developed by Bernanke and Gertler (1989) and Kiyotaki and Moore (1997), economic agents are more likely to be optimistic (pessimistic) about future house price movements during the bear (bull) market ${ }^{21}$. Although the prominence of financial constraints reinforces the impact of a contractionary monetary policy in the bear market, as suggested by Chen (2007) when analyzing stock markets, the response of house price inflation is likely to be short-lived due to the optimistic behaviour of economic agents which progressively outweighs the negative effect of a positive shock in the interest rate. On the other hand, the distinctive pessimistic behaviour of the bull regime tends to make the reaction of real house price growth rate prolonged but weaker to a positive monetary shock, since households are less financially constrained in this regime.

\footnotetext{
20 The interested reader is referred to the paper by Vargas-Silva (2008), Gupta et al. (2010, 2012a, b) for a detailed literature review.

${ }^{21}$ Backward looking, expectations would bring the opposite effect. This also suggests mean reversion, hence no bubbles.
} 
Table 3: EM Estimation for the MSIAH(2)-VAR(2), 1966:02-2011:12

\begin{tabular}{|c|c|c|c|c|c|c|c|c|c|}
\hline & \multicolumn{3}{|c|}{ All Segments } & \multicolumn{2}{|c|}{ Large segment } & \multicolumn{2}{|c|}{ Medium segment } & \multicolumn{2}{|c|}{ Small segment } \\
\hline & & Tbill & ghp & Tbill & ghp & Tbill & ghp & Tbill & ghp \\
\hline \multicolumn{10}{|c|}{ Regime dependent intercept } \\
\hline \multirow{2}{*}{$\mu_{1}$} & & $0.02^{*}$ & $0.11 *$ & $0.03^{* *}$ & 0.02 & $0.02^{*}$ & 0.08 & $0.03^{* *}$ & 0.04 \\
\hline & & $(0.013)$ & $(0.064)$ & $(0.013)$ & $(0.077)$ & $(0.014)$ & $(0.060)$ & $(0.013)$ & $(0.067)$ \\
\hline \multirow{2}{*}{$\mu_{2}$} & & 0.20 & $0.18^{* *}$ & $0.22 *$ & $0.29 * * *$ & 0.20 & $0.19 * *$ & 0.19 & $0.15^{* *}$ \\
\hline & & $(0.121)$ & $(0.062)$ & $(0.113)$ & $(0.062)$ & $(0.056)$ & $(0.064)$ & $(0.119)$ & $(0.072)$ \\
\hline \multicolumn{10}{|c|}{ Standards errors } \\
\hline \multicolumn{2}{|c|}{$\sigma_{1}$} & 0.09 & 0.46 & 0.08 & 0.57 & 0.09 & 0.44 & 0.09 & 0.5 \\
\hline & 0.61 & 0.28 & 0.60 & 0.30 & 0.61 & 0.28 & 0.60 & 0.31 \\
\hline \multicolumn{10}{|c|}{ Regime 1: Parameter estimates } \\
\hline$\beta_{1,1}$ & & $\begin{array}{l}1.36^{* *} \\
(0.043)\end{array}$ & $\begin{array}{l}-0.49 * * \\
(0.164)\end{array}$ & $\begin{array}{l}1.40 * * \\
(0.038)\end{array}$ & $\begin{array}{r}-0.19 \\
(0.192)\end{array}$ & $\begin{array}{l}1.35^{* *} \\
(0.053)\end{array}$ & $\begin{array}{r}-0.36^{* *} \\
(0.163)\end{array}$ & $\begin{array}{l}1.34^{* *} \\
(0.123)\end{array}$ & $\begin{array}{l}-0.44^{*} \\
(0.253)\end{array}$ \\
\hline$\beta_{1,2}$ & & $\begin{array}{l}-0.36^{* *} \\
(0.044)\end{array}$ & $\begin{array}{l}0.48^{* *} \\
(0.164)\end{array}$ & $\begin{array}{l}-0.40^{* *} \\
(0.037)\end{array}$ & $\begin{array}{r}0.18 \\
(0.192)\end{array}$ & $\begin{array}{l}-0.35^{* *} \\
(0.053)\end{array}$ & $\begin{array}{l}0.35^{* *} \\
(0.163)\end{array}$ & $\begin{array}{l}-0.35^{* *} \\
(0.123)\end{array}$ & $\begin{array}{r}0.44^{*} \\
(0.251)\end{array}$ \\
\hline$\beta_{2,1}$ & & $\begin{array}{r}0.02 \\
(0.012)\end{array}$ & $\begin{array}{l}0.21 * * \\
(0.061)\end{array}$ & $\begin{array}{r}0.01 \\
(0.010)\end{array}$ & $\begin{array}{l}0.66 * * \\
(0.064)\end{array}$ & $\begin{array}{r}0.02^{*} \\
(0.013)\end{array}$ & $\begin{array}{l}0.25^{* *} \\
(0.060)\end{array}$ & $\begin{array}{r}0.02 \\
(0.012)\end{array}$ & $\begin{array}{l}0.44^{* *} \\
(0.062)\end{array}$ \\
\hline$\beta_{2,2}$ & & $\begin{array}{r}0.01 \\
(0.012)\end{array}$ & $\begin{array}{l}0.29 * * \\
(0.061)\end{array}$ & $\begin{array}{l}-0.02^{* *} \\
(0.010)\end{array}$ & $\begin{array}{r}-0.09 \\
(0.065)\end{array}$ & $\begin{array}{l}-0.002 \\
(0.013)\end{array}$ & $\begin{array}{l}0.37 * * \\
(0.060)\end{array}$ & $\begin{array}{r}-0.01 \\
(0.013)\end{array}$ & $\begin{array}{l}0.19 * * \\
(0.063)\end{array}$ \\
\hline \multicolumn{10}{|c|}{ Regime 2: Parameter estimates } \\
\hline$\beta_{1,1}$ & & $\begin{array}{l}1.48 * * \\
(0.055)\end{array}$ & $\begin{array}{l}-0.08^{* *} \\
(0.026)\end{array}$ & $\begin{array}{c}1.48^{* *} \\
(0.054)\end{array}$ & $\begin{array}{r}-0.09 * * \\
(0.028)\end{array}$ & $\begin{array}{l}1.48^{* *} \\
(0.056)\end{array}$ & $\begin{array}{r}-0.1 * * \\
(0.027)\end{array}$ & $\begin{array}{l}1.49 * * \\
(0.055)\end{array}$ & $\begin{array}{l}-0.08^{* *} \\
(0.030)\end{array}$ \\
\hline$\beta_{1,2}$ & & $\begin{array}{l}-0.50^{* *} \\
(0.055)\end{array}$ & $\begin{array}{l}0.07 * * \\
(0.026)\end{array}$ & $\begin{array}{l}-0.50^{* *} \\
(0.054)\end{array}$ & $\begin{array}{l}0.07 * * \\
(0.028)\end{array}$ & $\begin{array}{l}-0.5 * * \\
(0.056)\end{array}$ & $\begin{array}{l}0.08^{* *} \\
(0.027)\end{array}$ & $\begin{array}{l}-0.50^{* *} \\
(0.055)\end{array}$ & $\begin{array}{l}0.07^{* *} \\
(0.030)\end{array}$ \\
\hline$\beta_{2,1}$ & & $\begin{array}{r}0.16 \\
(0.109)\end{array}$ & $\begin{array}{l}0.47 * * \\
(0.054)\end{array}$ & $\begin{array}{r}0.14 \\
(0.101)\end{array}$ & $\begin{array}{l}0.48 * * \\
(0.057)\end{array}$ & $\begin{array}{r}0.14 \\
(0.112)\end{array}$ & $\begin{array}{l}0.46^{* *} \\
(0.057)\end{array}$ & $\begin{array}{r}0.16 \\
(0.107)\end{array}$ & $\begin{array}{l}0.59 * * \\
(0.060)\end{array}$ \\
\hline$\beta_{2,2}$ & & $\begin{array}{r}-0.07 \\
(0.108)\end{array}$ & $\begin{array}{l}0.35^{* *} \\
(0.052)\end{array}$ & $\begin{array}{r}-0.08 \\
(0.097)\end{array}$ & $\begin{array}{l}0.26^{* *} \\
(0.054)\end{array}$ & $\begin{array}{r}-0.04 \\
(0.111)\end{array}$ & $\begin{array}{l}0.34 * * \\
(0.056)\end{array}$ & $\begin{array}{r}-0.08 \\
(0.105)\end{array}$ & $\begin{array}{l}0.21^{* *} \\
(0.058)\end{array}$ \\
\hline$\omega_{12 \_ \text {Tbill }}$ & & 0.015 & $1.8 \times 10^{-5}$ & 0.023 & 0.006 & 0.012 & $5.5 \times 10^{-4}$ & 0.003 & $2.4 \times 10^{-4}$ \\
\hline$\omega_{12 \_ \text {ghp }}$ & & 0.167 & 7.54 & 0.219 & 2.065 & 0.262 & 2.601 & 0.265 & 1.954 \\
\hline \multirow{2}{*}{ Fitting } & All se & egments & \multicolumn{2}{|c|}{ L Large segment } & \multicolumn{3}{|c|}{ "Medium segment } & \multicolumn{2}{|c|}{ Small segment } \\
\hline & $\begin{array}{l}\text { MSIAH- } \\
\text { VAR }\end{array}$ & $\begin{array}{l}\text { Linear } \\
\text { VAR }\end{array}$ & $\begin{array}{l}\text { MSIAH- } \\
\text { VAR }\end{array}$ & $\begin{array}{l}\text { Linear } \\
\text { VAR }\end{array}$ & & AH- & & $\begin{array}{l}\text { MSIAH- } \\
\text { VAR }\end{array}$ & $\begin{array}{l}\text { Linear } \\
\text { VAR }\end{array}$ \\
\hline LogLik & -315.14 & -587.78 & -393.62 & -683.07 & & & 7.28 & -369.20 & -631.68 \\
\hline AIC & 1.25 & 2.18 & 1.54 & 2.54 & & 2. & & 1.45 & 2.35 \\
\hline HQ & 1.33 & 2.23 & 1.62 & 2.58 & & & & 1.53 & 2.39 \\
\hline $\mathrm{SC}$ & 1.47 & 2.29 & 1.76 & 2.64 & & & & 1.67 & 2.45 \\
\hline
\end{tabular}

Note: Standard errors are in brackets. ${ }^{* * *},{ }^{* *}$ and $*$ indicate significance at $1 \%, 5 \%$ and $10 \%$ level of significance respectively. Terms $\omega_{12}$ Tbill ${ }^{\text {and }} \omega_{12 \_ \text {ghp }}$ are the Wald statistics for asymmetric effect (Equality of coefficients within regime 1 and regime 2):

$\beta_{1, \bar{j}}$ (regimel) $\quad \beta_{1, j}$ (regime2) and $\beta_{\overline{2, j}}$ (regime1) $\quad \beta_{2, j}$ (regime 2 ) for asymmetric effect of monetary policy and asymmetric feedback from house price shock respectively. The test statistic is $\chi^{2}$ with one degree of freedom under the null of symmetry. The critical values are 6.635, 3.841 and 2.706 at 1\%,5\% and 10\% respectively. AIC, SC and HQ are Akaike, Schwartzand Hannan-Quinn information criterion respectively. 
Figure 2: IRFs following a contractionary monetary policy shock across Bear and Bull market

Response to Tbill rate shock: All Segments
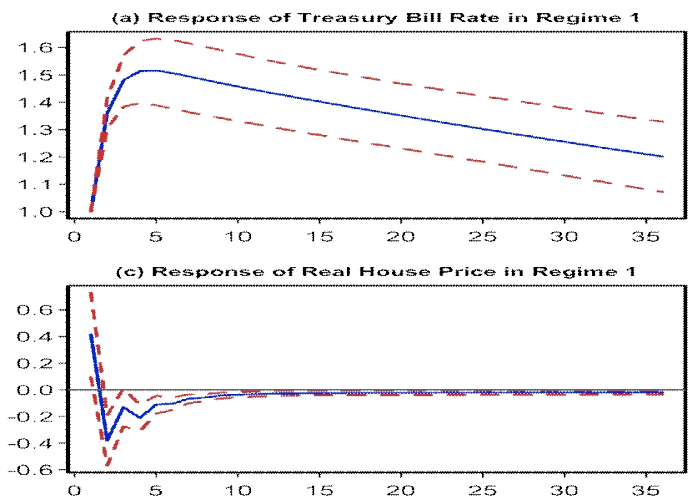

Response to Tbill rate shock: Large Segment
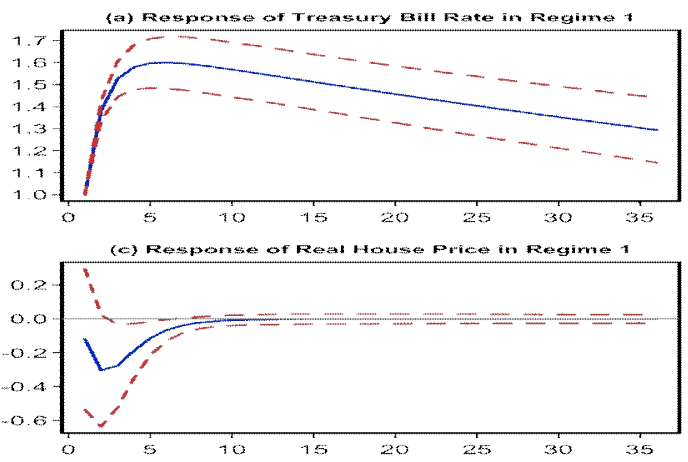

Response to Tbill rate shock: Medium Segment
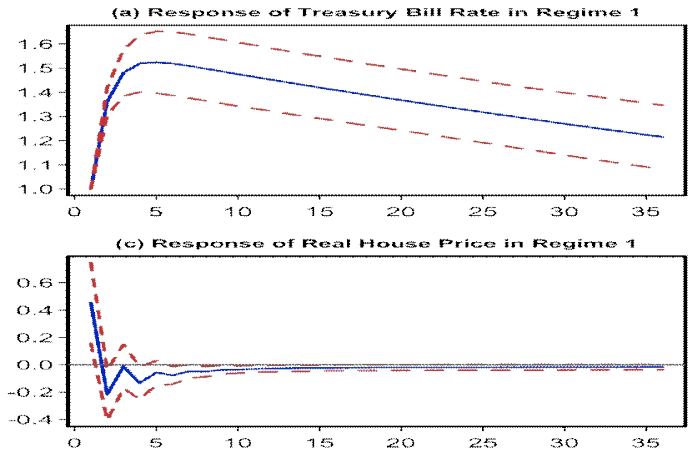

Response to Tbill rate shock: Small Segment
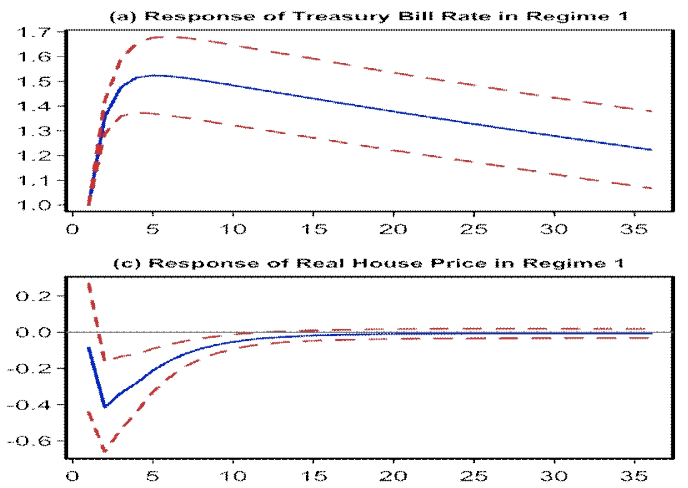

Note: on the left, IRFs in bear market (Regime 1). On the right, IRFs in bull market (Regime 2).
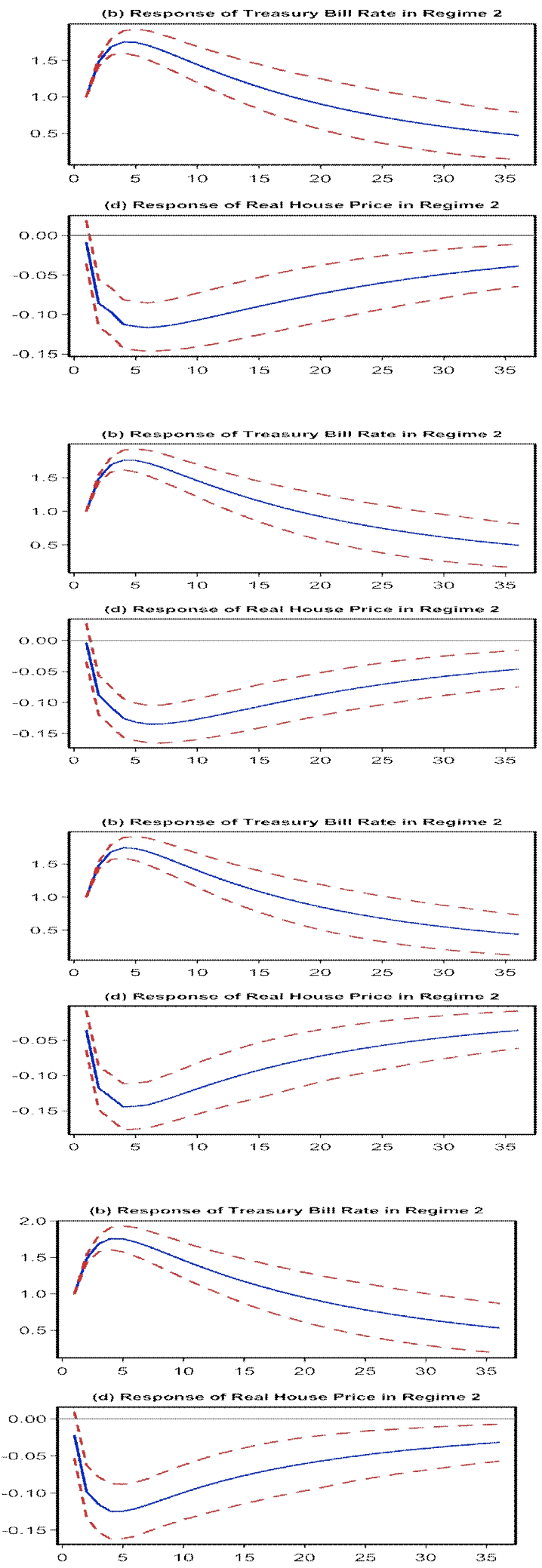
Figure 3: Responses of interest rate to a positive house price shock across Bear and Bull markets

Reponses to House Price Shock: All segments
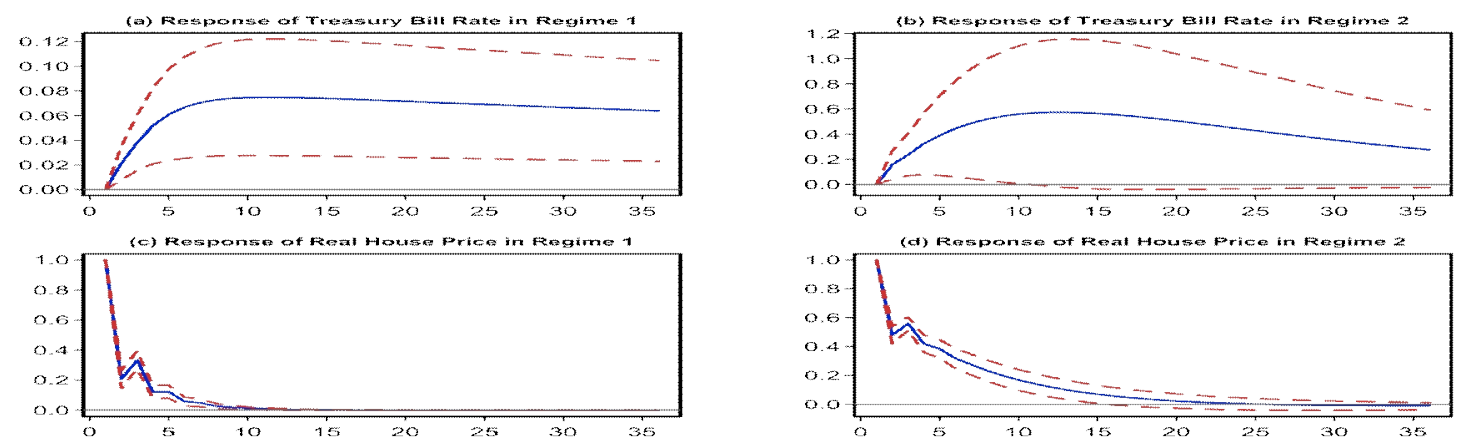

Reponses to House Price Shock: Large segment
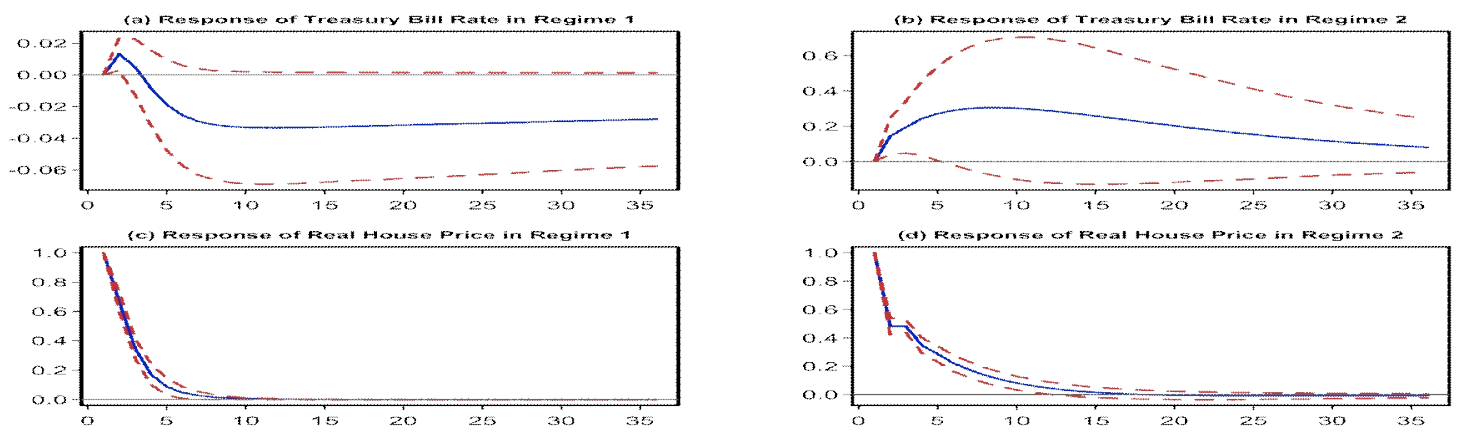

Reponses to House Price Shock: Medium segment
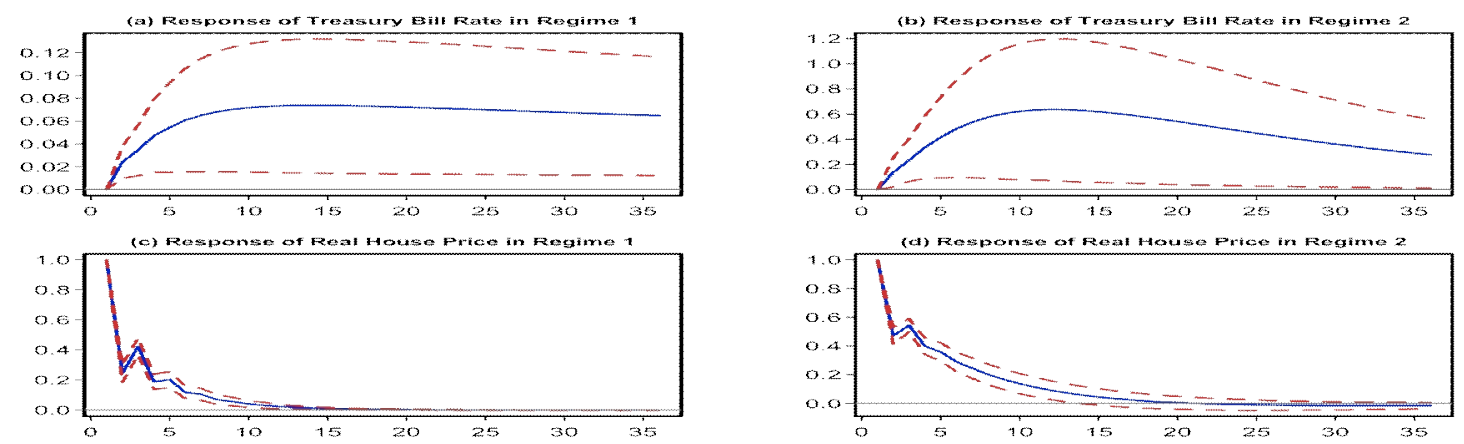

Reponses to House Price Shock: Small segment
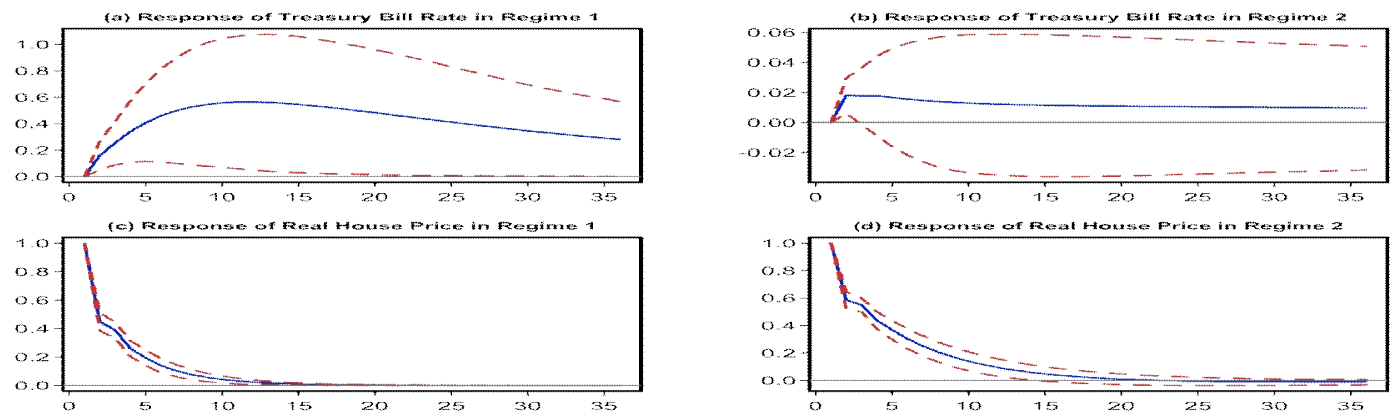

Note: on the left, IRFs in bear market (Regime 1). On the right, IRFs in bull market (Regime 2). 
Figure 3 displays the feedback from a house prices shock to monetary policy based on the IRFs following a 100 basis point shock to real house price growth. The reaction of house prices, following a positive shock in real house prices, dies out within a year in the bear market, while in the bull regime, the reaction lasts for about 15 months. The effects are similar within regimes, and across the different housing categories. The effect also remains consistently significant before reverting back to its equilibrium value. Though the effects might seem asymmetric visually, the Wald tests carried out in Table 2 on the autocorrelation coefficient tends to suggest that the impact on house prices, following a house price shock, are not statistically different across the regimes within the individual housing categories. In general the results indicate a positive response of monetary policy to a house price shock across the two states. The responses of interest rate following a shock in the entire (All) middle segment indicate that the reaction of monetary policy is stronger in the bull market, but the effect is significant for only a short period. This is not surprising, since the bull market tends to associated with house price bubbles (Helbling, 2005), and in order to prevent potential crisis related to the subsequent bust, the monetary authority might have a stronger reaction in this regime. Moreover, as economic agents are already pessimistic about future expectations in house price movements, the monetary policy reaction is likely to be big but quick one. Besides this, given that the movement in the house prices in South Africa is found to have a positive impact on the prices of non-housing goods and services (Gupta and Inglesi-Lotz, forthcoming), and which is likely to be bigger in magnitude during the bull market, the relatively stronger reaction of monetary policy to house price shock is justified in this regime to prevent inflationary pressures. Furthermore, when the housing market is in the bear regime, causing the economy to be in recession via the wealth effect (Ncube and Ndou, 2011; Peretti et al., forthcoming; Simo-Kengne et al., 2012, forthcoming), the central bank is likely to be more conservative but more persistent in its response to house price increases.

However, diverse patterns emerge with respect to different models. In terms of magnitude, the reaction of monetary policy is stronger in the bull regime, relative to the bear regime, for the large and medium middle-segments, with the positive effect for the large segment under the bull regime lasts for a way shorter period when compared to the medium segment. These results, especially for the medium segment, are in line with the findings for the entire middle-segment, but contrast with the small segment, in which a stronger and more persistent reaction of monetary policy is obtained in the bear regime. The observed difference could be possibly attributed to the dual feature of housing as being both a consumption and investment good simultaneously ${ }^{22}$. In effect, small segment houses are believed to act as an investment good for relatively richer households who resides in mainly the luxury segment of the market or the large middle-segment (Inglesi-Lotz and Gupta, forthcoming). Bear markets are more a buyer's market, in light of this, richer homeowners might want to spend some of their wealth to acquire property in the small segment as investment. The resulting increase in housing demand coupled with the typical optimism of the bear regime might lead to increase inflation or financial stability risks in a low interest environment, causing the monetary authority to respond more to a positive house price shock in the bear regime of small-segment housing. At this stage, it is perhaps worth noting that even though the SARB is likely to monitor house prices of all the segments of the housing market, it is most likely that it would want to respond to an average price of the housing sector ${ }^{23}$, which in our case happens to be the house price of the aggregate middle segment. Given this, the response of the monetary authority following a house price shock to the entire middle segment, could be depicting its typical response. However, having said this, our results do provide

\footnotetext{
${ }^{22}$ Alternatively, since investors need to be leveraged, credit quality concerns might be higher in the lower segment for owner-occupiers during busts, as fall in income and unemployment risks are higher.

23 Alternatively, credit profiles may vary across segments, implying different risks for the economy and for financial stability.
} 
evidence that the interest rate responds significantly to the house price movements of the different segments of the market.

\section{Conclusion}

This paper investigates whether the impact of monetary policy shock on the entire middlesegment of the South African housing market, and its three categories based on sizes, is asymmetric using a MS-VAR approach spanning the period of 1966:M2 to 2011:M12. We find that monetary policy is non-neutral, as a contractionary monetary policy significantly depresses real house prices irrespective of house sizes. Furthermore, important asymmetries are found in the dynamics of house prices following a monetary policy shock in the bull and bear regimes identified for the housing market. Monetary policy is found to have larger effect on real house price inflation during the bear market-regime, thus supporting theoretical models that suggest the role of information asymmetry in reinforcing financial constraints of economic agents during this regime. This finding is robust to the aggregate and the various house sizes within the middlesegment.

Given that we used a MS-VAR to account for a possible feedback effect of house price movements on monetary policy setting, we also analyzed the impact on the interest rate following a house price shock. We found evidence of positive feedbacks from housing prices to the interest rate, which, in turn, confirmed that monetary policy in South Africa reacts to house price shocks, with the SARB found to respond more to a positive house price shock in the bull regime. This is not surprising, given that a bull market is possibly associated with house price bubbles, thus leading the monetary authority to react stronger in this regime in an attempt to prevent economic recession due the subsequent bust. Also, house price increases are likely to be more inflationary in the bull-regime than the bear regime, due to a bigger impact on the aggregate demand via the wealth effect of real house price increases. Finally, while the effect of monetary policy is consistent across house sizes in general, the reaction of the central banker to a house price shock in the small sized middle segment contrasts the remaining categories. In this segment, the reaction of monetary policy is found to be stronger in the bear regime; suggesting that houses in the small-segment are more likely to be investment goods and hence, are more attractive in the bear regime given the optimism of economic agents which, in turn, motivates a stronger response from the monetary authority to prevent possible inflationary pressures.

On the other hand, there is also some evidence that house price expectations are, at least to some extent, backward-looking. This is reflected by the fact that house prices show inertia and follow long cycles, plausibly displaying bubbles. Monetary authorities may, therefore, respond more in a bear market because they are concerned with credit quality and financial stability, more than by inflation prospects, which would be benign in a bear market (unless the housing market is disconnected from the rest of the economy). It is also possible that the lower segment of the market is more representative of wider economic conditions than higher segments, where buyers might be less credit constrained and where there may be more support for prices (for example because of better locations, foreign buyers). Hence a pick-up in lower segment prices may provide a stronger signal for normalising interest rates when those are low in a bust. 


\section{References}

Andre C., Gupta, R. and Kanda, P.T. (2011). Do house prices impact consumption and interest rate? Evidence from OECD countries using an agnostic identification procedure. OECD Economics Department Working Paper No. 947.

Aron, J. and Muellbauer, J. (2007). Review of monetary policy in South Africa since 1994. Journal of African Economies, 16(5):705-744.

Bernamke, B.S. and Gertler, M. 1989. Agency costs, net worth and business fluctuations. American Economic Review, 79(1):14-31.

Cartensen, K., Hulsewig, O. And Wollmershauser, T. (2009). Monetary policy transmission and house prices: European cross country Evidence. CESifo Working Paper No. 2750,

Chang, K.L., Chen, N.K. and Leung, C.K. (2011). Monetary policy, term structure and asset return: Comparing REIT, housing and stock. Journal of Real Estate Finance and Economics, 43(1): 221-257.

Chen, S-S. (2007). Does monetary policy have symmetric effects on stock returns? Journal of Money, Credit and Banking, 39(2-3):667-688.

Chib, S. (1996). Calculating posterior distributions and modal estimates in Markov mixture models. Journal of Econometrics, 75:79-97.

Das, S., Gupta, R. and Kanda, P.T. (2011). Bubbles in South African house prices and their impact on consumption. Journal of Real Estate Literature, 19(1):71-91.

Davies, R.A. (1977). Hypothesis testing when a nuisance parameter is present only under the alternative. Biometrika, 64:247-254.

Demary, M. 2010. The interplay between output, inflation, interest rates and house prices: International evidence Journal of Property Research, 27(1):1-17.

Dickey, D. and Fuller, W. 1981. Likelihood ratio statistics for autoregressive time series with a unit root. Econometrica, 49:1057-1072.

Doornik, J.A. and Hansen, D. (1994). An omnibus test for univariate and multivariate normality. Working Paper, Nuffield College, Oxford.

Ehrmann, M., Ellison, M. and Valla, N. (2003). Regime-dependent impulse response functions in a Markov-switching vector autoregression model. Economics Letters, 78:295-299.

Elliot, G., Rothenberg, T.J. and Stock, J.H. 1996. Efficient tests for an autoregressive unit root. Econometrica, 64:813-836.

Feng, L. and Li, W. (2011). Specification of housing bubbles based on Markov Switching Mechanism: A case of Beijing. Communications in Computer and Information Science, 211:134140.

Garino, G. and Sarno, L. (2004). Speculative bubbles in U.K. house prices: Some new evidence. Southern Economic Journal, 70(4):777-795.

Giuliodori, M. (2005). Monetary policy shocks and the role of house prices across European countries. Scottish Journal of Political Economy, 52(4):519-543.

Gupta, R. (2012). Forecasting house prices for the four census regions and the aggregate US economy: The role of a data-rich environment. Working Paper No. 14/2012,Department of Economics, University of Pretoria.

Gupta, R. and Inglesi-Lotz, R. (forthcoming). Relationship between house prices and inflation in South Africa. An ARDL approach. International Journal of Strategic Property Management.

Gupta, R. and Kabundi, A. (2010). The effect of monetary policy on house price inflation: A factor augmented vector autoregression (FAVAR) approach. Journal of Economic Studies, 37(6):616-626.

Gupta, R., Jurgilas, M. and Kabundi, A. (2010). The effect of monetary policy on real house price growth in South Africa: A factor augmented vector autoregression (FAVAR) approach. Economic modelling, 27(1):315-323. 
Gupta, R. and Hartley, F. (forthcoming). The role of asset prices in forecasting inflation and output in South Africa. Journal of Emerging Market Finance.

Gupta, R.Jurgilas, M., Kabundi, A. And Miller, S.M.(2012a). Monetary policy and housing dynamics in a large-scale Bayesian Vector Autoregressive model. International Journal of Strategic Property Management, 16(1): 1-20.

Gupta, R., Jurgilas, M., Miller, S.M. and van Wyk, D. (2012b). Financial market liberalisation, monetary policy and housing price dynamics. International Business and Economics Research Journal, 11(1):69-82.

Gupta, R. and Ndahiriwe, K. (2010). Financial liberalization and the effectiveness of monetary policy on house prices in South Africa. The IUP Journal of Monetary Economics, 8(4):59-74.

Gupta, R. and Reid, M. (2012). Macroeconomic surprises and stock returns in South Africa, Working paper No. 05/2012, Depatment of Economics, University of Stellenbosch.

Golfeld, S.M. and Quandt, R.E. (1973). A Markov model for switching regressions. Journal of Econometrics, 1:3-16.

Goodhart, C. and Hofmann, B. 2008. House prices, money, credit, and the macroeconomy. Oxford Review of Economic Policy, 24(1):180-205.

Helbling, T. (2005). Housing price bubbles- a tale based on housing price booms and busts. BIS Paper, 21:30-41.

Hall, S., Psaradakis, Z. and Sola, M. (1997). Switching error-correction models of house prices in the United Kingdom. Economic Modelling, 14(4):517-527.

Hamilton, J.D. (1989). A new approach to the economic analysis of nonstationary time series and the business cycle. Econometrica, 57:357-384.

Harding, D. And Pagan, A. (2006). Synchronisation of cycles. Journal of Econometrics, 132:59-79.

Jansen, D.W. and Tsai, C.L. (2010). Monetary policy and stock returns: financing constraints and asymmetries in bull and bear markets. Journal of Empirical finance, 17(5):981-990.

Kiyotaki, N. And Moore, J. (1997). Credit cycles. Journal of Political Economy, 105(2):211-248.

Koetze, N.J. (1999). The influence of residential desegregation on property prices in South Africa: The Pietersburg case study. Tydskrif Vir Gesinsekologie en Verbruikerswetenskappe, $27(1): 48-54$.

Krolzig, H.M. (1997). Markov switching vector autoregressions: modelling, statistical inference and application to business cycle analysis. Lecture Notes in Economics and Mathematical Systems. No. 454, Berlin: Springer-Verlag.

Krolzig, H.M. (1998). Econometric modelling of Markov-Switching vector autoregressions using MSVAR for OX, Department of Economics, University of Oxford.

Kwiatkowski, D., Phillips, P., Schmidt, P. and Shin, J. 1992. Testing the null hypothesis of stationarity against the alternative of a unit root. Joumal of Econometrics, 54:159-178.

Leamer, E.E. 2007. Housing is the business cycle. Working Paper 13428, National Burean of Economic Research.

Luüs, C. (2005). The Absa residential property market database for South Africa_ key data trends and implications. BIS Paper No. 21:149-170.

McCarthy, J. and Peach, R. (2002). Monetary policy transmission to residential investment. Economic policy review, 139-158.

Mishkin, F.S. (2007). Housing and the monetary transmission mechanism. Working Paper No. 13518, National Bureau of Economic Research.

Musso, A., Neri, S. and Stracca, L. 2011. Housing, consumption and monetary policy: how different are the US and the Euro area? Journal of Banking and Finance, 35(11):3019-3041.

Napolitano, O. (2006). Is the impact of ECB monetary policy on EMU stock market returns asymmetric? Working Paper No. 3.2006, Universita Degli Studi Di Napoli. 
Naraidoo, R. and Ndahiriwe, K. Forthcoming. Financial asset prices, linear and nonlinear policy rules. An in-sample assessment of the reaction function of the South African Reserve Bank. Journal of Economic Studies.

Naraidoo, R and Raputsoane, L. 2010. Zone-targeting monetary policy preferences and financial market conditions: a flexible non-linear policy reaction function of the SARB monetary policy. South African Journal of Economics, 78(4):400-417.

Ng, S. and Perron, P. 2001. Lag length selection and the construction of unit root tests with good size and power. Econometrica, 69:1519-1554.

Ncube, M. and Ndou, E. (2011). Monetary policy transmission, house prices and consumer spending in South Africa: An SVAR approach. Working Paper No 133, African Development Bank Group.

Newey, W.K. and West, K. D. (1987). A simple, positive semi-definite, heteroskedasticity and autocorrelation consistent covariance matrix. Econometrica, 55:703-708.

Peretti, V., Gupta, R. and Inglesi-Lotz, R. (forthcoming). Do house prices impact consumption and interest rate in South Africa? Evidence from a Time Varying Vector Autoregressive model. Economics, Financial Markets and Management.

Perlin, M. 2011. Ms Regress: the MATLAB package for Markov regime switching models, Working Paper, University of Reading and Universidade Federal do Rio Grande do Sul.

Phillips, P. and P. Perron. 1988. Testing for a unit root in time series regression. Biometrika, 75:335-346.

Prinsloo, D.A. and Cloete, C.E. (2002). Post-Apartheid residential mobility patterns in two South African cities. Property Management, 20(4):264-277.

Quandt, R.E. (1960). Test of hypotheses that a linear system obeys two separate regimes. Journal of the American Statistical Association, 55:324-330.

Simo-Kengne, B.D., Bittencourt, M. and Gupta, R. (2012). House prices and economic growth in South Africa: Evidence from provincial level data. Journal of Real Estate Literature, 20(1):97-117.

Simo-Kengne, B.D., Bittencourt, M. and Gupta, R. (forthcoming). The impact of house prices on consumption in South Africa: Evidence from panel VARs. Housing Studies.

Smets, F. 2007. Commentary: Housing is the business cycle.

http://www.kansascityfed.org/publicat/sympos/2007/pdf/Smets 0415.pdf

Vargas-Silva, C. (2008). Monetary policy and the US housing market: A VAR analysis imposing sign restrictions. Journal of Macroeconomics, 30(3):977-990.

White, H., (1980). A heteroskedastic-consistent covariance matrix estimator and a direct test for heteroskedasticity. Econometrica, 48:817-838.Xiao, Q. and Tan, G.K.R. (2006). Markovswitching unit root test: A study of the property prices bubbles in Hong Kong and Seoul. Working Paper No. 2006/02, Economic Growth Centre. 